\title{
Preservation and restoration of sphincter function in patients with rectal cancer
}

\author{
Rudolf Schiessel MD, Harald R Rosen MD
}

\begin{abstract}
R Schiessel, HR Rosen. Preservation and restoration of sphincter function in patients with rectal cancer. Can J Gastroenterol $2000 ; 14(5): 423-426$. Radical resection of rectal cancer is the standard treatment for curing this disease. Half of these tumours are located in the rectosigmoid region or the upper third of the rectum and are, therefore, easily resectable with preservation of the sphincter muscles, thus guaranteeing acceptable continence in most patients. However, tumours that originate in the lower parts of the rectum have been accompanied with the need for an abdominoperineal resection and the threat of a permanent colostomy. In the past 20 years, sphincter-saving surgery has become increasingly common in the treatment of tumours of the middle and low rectum due to the knowledge of tumour growth, the use of stapling devices, and the knowledge of the physiology of the pelvic floor and the sphincter muscles, respectively. Recent surgical techniques of resection of the 'ultralow' rectum (intersphincteric resection) and the reconstruction by coloanal anastomosis are reviewed.

Functional problems following ultralow resections are emphasized, as well as the possibility of sphincter restoration after abdominoperineal resection by use of dynamic graciloplasty. Taking all surgical options into account, a permanent colostomy for rectal cancer can be avoided in most curatively and electively operated patients.
\end{abstract}

Key Words: Intersphincteric resection; Rectal cancer

\section{Préservation et rétablissement de la fonction sphinctérienne chez les patients atteints d'un cancer du rectum}

RÉSUMÉ : Le traitement usuel du cancer du rectum est la résection radicale. La moitié des tumeurs siègent dans la région recto-sigmoïdienne ou dans le tiers supérieur du rectum et sont, par conséquent, facilement résécables tout en préservant les muscles sphinctériens, ce qui garantit une continence acceptable chez la plupart des patients. Cependant, les tumeurs qui siègent dans les parties basses du rectum nécessitent une résection abdomino-périnéale et, dans bien des cas, une colostomie définitive. Au cours des vingt dernières années, on a eu de plus en plus recours à la chirurgie épargnant le sphincter pour traiter les tumeurs situées dans les parties basse et moyenne du rectum grâce à l'utilisation de dispositifs d'agrafage et à une meilleure connaissance de la croissance des tumeurs et de la physiologie des structures périnéales et des muscles sphinctériens. Le présent article passe en revue les dernières techniques de résection chirurgicale de la partie ultra-basse du rectum (résection intersphinctérienne) et de reconstruction grâce à l'anastomose colo-anale. Il sera surtout question des problèmes fonctionnels consécutifs à une résection ultra-basse et des possibilités de rétablissement de la fonction sphinctérienne par la graciloplastie dynamique après une résection abdomino-périnéale. Compte tenu de toutes les options chirurgicales, on constate qu'il est possible d'éviter la colostomie permanente chez la plupart des patients qui subissent une intervention chirurgicale non urgente et curative pour le traitement d'un cancer du rectum.
$\mathrm{S}_{\mathrm{c}}^{\mathrm{u}}$ urgery is the most important form of treatment for rectal cancer by radical local tumour control. Despite that recurrence-free survival is still the major goal of surgical therapy, it is also widely accepted that the surgeon should relieve distressing symptoms associated with the procedure.

A major concern of patients with colorectal cancer is the possibility that surgery leads to a permanent stoma. In the 'early days' of rectal surgery, abdominoperineal resection (APR) of the rectum with construction of a permanent colostomy was the treatment of choice for patients with cancer located in the middle or lower third of the rectum. Intramural spread of cancer and the possibility of lymphogenic

This mini-review was prepared from a presentation made at the World Congress of Gastroenterology, September 6 to 11, 1998, Vienna, Austria Ludwig Boltzmann Research Institute for Surgical Oncology, Danube Hospital, Vienna, Austria

Correspondence and reprints: Dr Rudolf Schiessel MD, Ludwig Boltzmann Research Institute for Surgical Oncology, Danube Hospital/SMZ-Ost, Langobardenstr 122, A-1220 Vienna, Austria. Telephone +43-1-288 02 3302, fax +43-1-28802 3380, e-mail

Helene.Charwat@smz.maguin.gr.at 


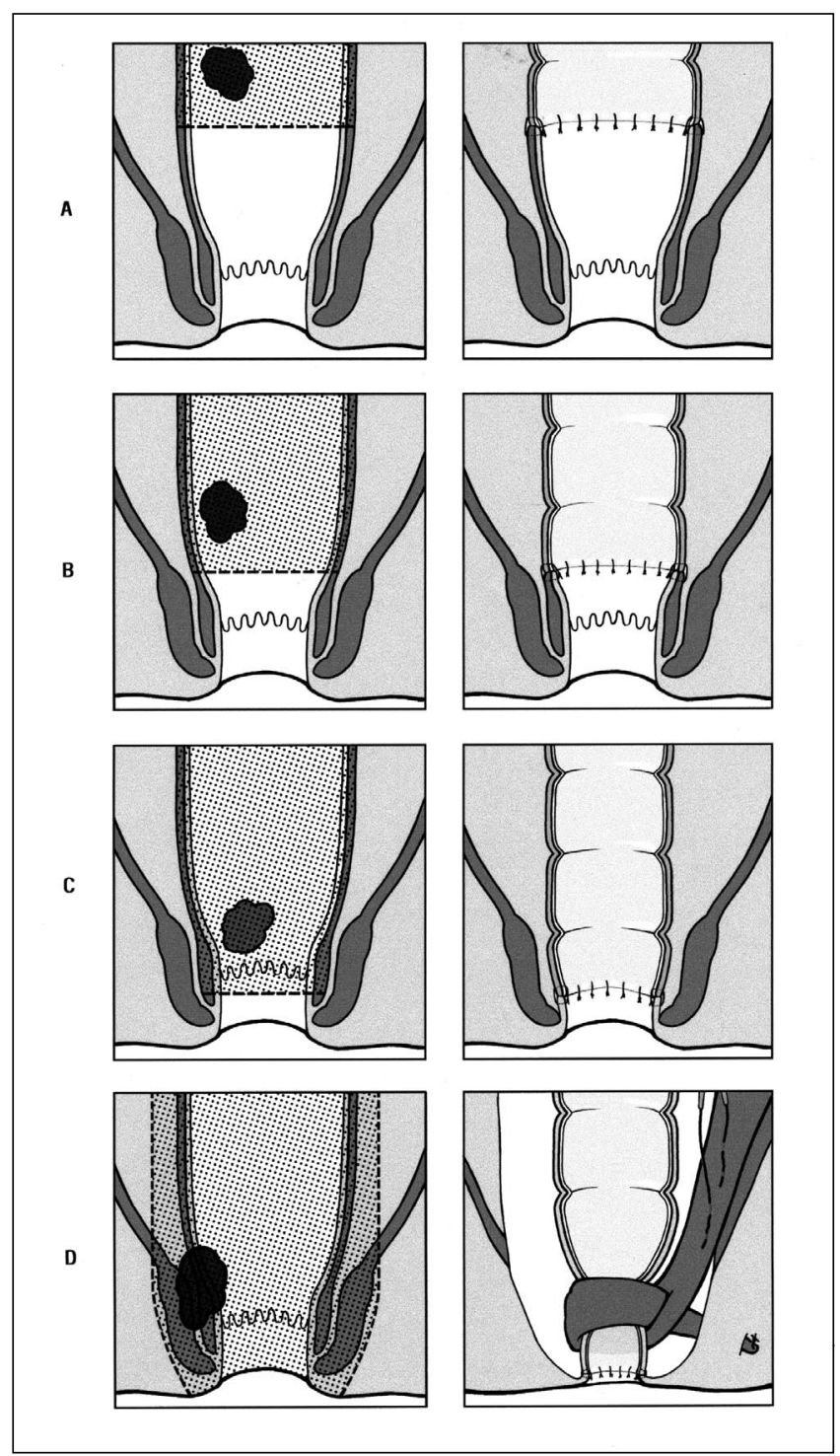

Figure 1) Surgery of rectal cancer. Resection and reconstruction according to the localization of tumour. A Anterior resection with hand-sewn or stapled anastomosis. B 'Ultralow' resection with coloanal anastomosis. C 'Ultralow', intersphincteric resection with coloanal anastomosis. D Abdominoperineal resection with sphincter replacement by dynamic graciloplasty

spread via the aboral route were major concerns and led to the recommendation of a safety distance of at least $5 \mathrm{~cm}$ from the distal tumour margin to prevent local recurrence (1).

As a result of more recent studies, it is now widely accepted that intramural spread rarely exceeds $1 \mathrm{~cm}$ and that patients in whom an intramural spread wider than $1 \mathrm{~cm}$ is observed are usually diagnosed in a more advanced tumour stage, including the lymph node metastases stage $(2,3)$. This knowledge, as well as the knowledge that the lymphogenic spread of rectal cancer has a cephalad direction and occurs along the mesorectum to the inferior mesenteric artery, have led to a change in the surgical approach for local control of rectal cancer.

Complete excision of the mesorectum and a distal tu- mour-free margin of $2 \mathrm{~cm}$ are the essential criteria for minimizing the risk of local recurrence (4).

Removal of the sphincter apparatus does not substantially increase the radicality of the surgery, provided that the sphincter is not infiltrated by the tumour. Is sphincter-saving surgery, therefore, less radical than APR?

Several studies have demonstrated that sphincter-saving surgery does not impair radicality $(5,6)$. The local recurrence rate, which is the best parameter to evaluate the efficacy of local tumour control, has been shown to be similar in comparable groups treated by APR or sphincter preservation.

Although the above-mentioned changes as well as the progress in surgical techniques have reduced the amount of rectal cancer patients needing a permanent stoma to about $20 \%$ in specialized centres, this rate is considerably higher, up to $40 \%$ to $50 \%$, in less specialized surgical departments (7).

The surgical techniques available to restore continuity depend on the level of dissection of the rectum. In cases where the rectal stump is of sufficient length, the descending colon is anastomosed by hand or by the more popular stapling gun (Figure 1). This is the most common sphinctersaving method and is the classical 'anterior resection'.

Complete excision of the rectum down to the level of the levator ani requires an anastomosis with the anal canal - a 'coloanal anastomosis'.

The principles of this technique were described in 1888 by Hochenegg (8), who advocated a sacral approach to the rectum. Later, pullthrough procedures via an abdominal route, with or without eversion of the anorectal stump, were reported by others $(9,10)$. However, due to the technical difficulties and the high morbidity associated with these procedures, APR was regarded as the method of choice until the modern technique of transanal resection and coloanal anastomosis was presented by Parks (11) in 1972.

By using this technique, resection of the rectum may be extended into the anal canal by removing the internal sphincter completely or partially ('intersphincteric resection'), thus offering the opportunity for sphincter-preserving resections of tumours below $5 \mathrm{~cm}$ from the dentate line.

In general, ultralow resection of rectal cancer with coloanal anastomosis is associated with an acceptable postoperative morbidity and oncological results in the literature (12). Mortality in most series is below $10 \%$, and the most common complications are urinary and sexual problems (comparable with those associated with APR). Interestingly, clinically relevant insufficiency of the coloanal anastomosis seems to be a rare problem, and pelvic sepsis is observed in larger series in less than $10 \%$ of cases $(13,14)$. The explanations for this finding are mainly speculative and include the high experience in rectal surgery of most of the authors, the use of a protective stoma in most series or the (extraperitoneally performed) anastomosis outside the abdomen in the anal canal.

It is widely accepted that oncological results achieved with ultralow resection of rectal cancer are acceptable and that the local recurrence rate is in the range of $10 \%$. However, there are still candidates for APR. In a series of 134 
patients treated by ultralow resection and coloanal anastomosis at the Memorial Sloan-Kattering Cancer Center, the following parameters correlated with a high risk for local recurrence (14): tumour size, perineural or vascular invasion of tumour cells, high histological grade (G III), carcinomatosis of the mesentery and tumour invasion of the resection margins. Therefore, patients having tumours with infiltration of the external anal sphincter as well as of the Musculus levator ani, or with a high grade malignancy close to the anus certainly need APR.

However, sphincter removal does not necessarily mean that the patient has to live with a permanent colostomy. A new technique, dynamic graciloplasty, allows replacement of the anal sphincter by a transposition of the gracilis muscle from the leg as a 'neosphincter'.

Knowledge of the effects of controlled, chronic, low frequency stimulation of the skeletal muscles has led to the 'revival' of a procedure reported by Pickrell in 1952 (15-17). Electrostimulation of the transposed gracilis muscle by an implanted pulse generator causes transformation of fasttwitching type II muscle fibres to slow-twitching (and fatigue-resistant) type I fibres. Following a conversion (training) period of four to eight weeks, the gracilis muscle is able to contract continuously (tetanic contraction) for $24 \mathrm{~h}$. The electronic stimulator can be controlled by the patient with a remote control so that the muscle can be relaxed for defecation.

How is bowel function after sphincter salvage or replacement? In general, continence function is reported to be fairly good, even after extensive rectal resection and ultralow or coloanal anastomosis.

Major problems are the loss of the reservoir function of the rectum causing high stool frequencies, fragmentation and other problems (18). Encouraging results of the use of restorative (mainly J-) colon pouches to obviate these problems have been reported $(19,20)$. Although two randomized trials have reported a superiority of colonic pouches over the straight coloanal anastomosis, it is widely accepted that these benefits are mainly evident during the first two postoperative months and that approximately $75 \%$ of patients with straight coloanal anastomosis improve considerably during the first postoperative year. However, a subgroup of patients (approximately 10\%) with colonic pouches complain of severe defecation problems, including fecal impactions and evacuation disorders, and require irrigation or enemas permanently.

A recently published method (21) may offer a promising alternative to increase the (neo) rectal compliance following low resection. A Swiss group described a new pouch created in an experimental pig model designed by performing a mere longitudinal colotomy of the taenia libera coli followed by a transverse closure. Although the pouch volume of this new pouch was significantly smaller than that obtained with a J-pouch, the frequency of defecation was comparable.

Clinical application of this new method may overcome severe technical problems in obese patients or in patients with a long anal canal in whom the distal resection margin and the anastomosis are situated in the dentate line, and in whom construction of a J-pouch is almost technically impossible.

Although dynamic graciloplasty has provided excellent results in patients who were operated for fecal incontinence due to major sphincter defects, the use of this technique for sphincter restoration following APR is regarded as a compromise (22).

Despite sufficiently high sphincter pressures created by the transformed gracilis muscle, defecation disorders, including incomplete evacuation and subsequent episodes of incontinence, are the major functional problems following this procedure. Most patients require periodical enemas or irrigation following APR to empty their neorectum sufficiently. Although a satisfying functional result can be achieved in $60 \%$ to $75 \%$ of patients by this method, an intensive preoperative interview as well as a close follow-up after the procedure are mandatory to avoid disappointment.

A further point of controversy with this method is the selection of patients. The possible risk of recurrence and early death after such an expensive procedure raises a cost-benefit concern, depending mainly on the local financial and insurance situation of the different institutions. As possible solutions for this problem, a one-stage procedure (APR, muscle transposition and implant of stimulation electrodes and pulse generator) or a secondary total anorectal reconstruction (TAR) may be offered (17).

While the one-stage procedure provides muscle restoration with acceptable continence (with or without irrigation) within approximately eight weeks (thus providing a good quality of life even for patients with a shorter survival), secondary TAR is selectively performed in patients one to two years after APR. The chance of local recurrence is reduced with secondary TAR, and only patients who definitively cannot bear having a permanent colostomy are selected for this procedure. However, although secondary TARs have been performed with satisfying results, it must be emphasised that they is technically more challenging than TARs done synchronously during APR.

\section{CONCLUSIONS}

Progress in surgical techniques, and in the knowledge of colorectal physiology and the nature of rectal cancer, have augmented the therapeutic options, providing almost all rectal cancer patients who are candidates for elective and radical surgery the opportunity to live without a permanent colostomy.

In a recent study in our department (22), we demonstrated that in the elective and curative situation, no patient needed a permanent stoma for the treatment of rectal cancer.

\section{REFERENCES}

1. Dukes CE. The spread of cancer of the rectum. Br J Surg 1930;17:643-8.

2. Goligher JC, Dukes CE, Bussey HJR. Local recurrence after sphincter-saving excisions for carcinoma of the rectum and rectosigmoid. Br J Surg 1951;39:199-211.

3. Pollet WG, Nicholls RJ. The relationship between the extent of distal clearence and survival and local recurrence after curative resection for carcinoma of the rectum. Ann Surg 1983;198:159-63. 
4. Mac Farlane JK, Ryall RDH, Heald RJ. Mesorectal excision for rectal cancer. Lancet 1993;341:457-60.

5. Williams NS, Johnston D. Survival and recurrence after sphincter saving resection and abdominoperineal resection for carcinoma of the middle third of the rectum. Br J Surg 1984;71:278-82.

6. Odou MW, O'Connel TX. Changes in the treatment of rectal carcinoma and effect on local recurrence. Arch Surg 1986;121:1114-6.

7. Leo E, Belli F, Baldini MT, et al. New perspectives in the treatment of low rectal cancer: total resection and coloendoanal anastomosis. Dis Colon Rectum 1994;37(Suppl):S62-8.

8. Hochenegg J. Die sakrale Methode der Exstirpation von Mastdarmkrebsen nach Prof. Kraske. Wien Klin Wochenschr $1888 ; 1: 272-354$

9. Sebrechts J. Discussions on the conservative surgery of carcinoma of the rectum. Proc R Soc Med 1935;28:1563-5.

10. Babcock WW. Experiences with resection of the colon and elimination of colostomy. Am J Surg 1939;46:186-303.

11. Parks AG. Transanal technique in low rectal anastomoses. Proc R Soc Med 1972;65:975-6.

12. Schiessel R, Karner-Hanusch J, Herbst F, Wunderlich M. Intersphincteric resection for low rectal tumours. Br J Surg 1994;81:1376-8.

13. Braun J, Teutner H, Winkeltau G, Schumpelick V. Results of intersphincteric resection of the rectum with direct coloanal anastomosis for rectal carcinoma. Am J Surg 1992;163:407-12.

14. Paty PB, Enker WE, Cohen AM. Treatment of rectal cancer by low anterior resection with coloanal anastomosis. Ann Surg 1994;219:365-73.
15. Pickrell KL, Broadbent TR, Masters FW, et al. Construction of a rectal sphincter and restoration of anal continence by transplanting the gracilis muscle. Ann Surg 1952;135:853-62.

16. Williams NS, Patel J, George RD, Hallan RI, Watkins ES. Development of an electrically stimulated neoanal sphincter. Lancet 1991;338:1166-9.

17. Rosen HR, Novi G, Zoech G, Feil W, Urbarz C, Schiessel R. Restoration of anal sphincter function by single-stage dynamic graciloplasty with a modified (split-sling) technique. Am J Surg 1998;175:187-93.

18. Carmona A, Ortiz H, Perez Cabanas I. Alterations in anorectal function after anterior resection for cancer of the rectum. Int J Colorectal Dis 1991;6:108-10.

19. Seow-Choen F, Goh HS. Prospective randomized trial comparing $\mathrm{J}$ colonic pouch-anal and straight coloanal reconstruction. Br J Surg 1995;82:608-10

20. Berger A, Tiret E, Parc R, et al. Excision of the rectum with colonic J pouch - anal anastomosis for adenocarcinoma of the low and mid rectum. World J Surg 1992;16:470-7.

21. Z'graggen K, Maurer CA, Mettler D, et al. A novel colon pouch and ist comparison with a straight coloanal and colon J-pouch-anal anastomosi: preliminary results in pigs. Surgery 1999;125:105-12.

22. Madoff RD, Rosen HR, Baeten CG, et al. Safety and efficacy of dynamic muscle plasty for anal incontinence: lessons from a prospective, multicenter trial. Gastroenterology 1999;116:549-56.

23. Renner K, Rosen HR, Novi G, Hölbling N, Schiessel R. Quality of life after surgery for rectal cancer: do we still need a permanent colostomy? Dis Colon Rectum 1999;42:1160-7. 


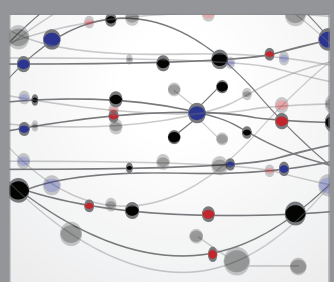

The Scientific World Journal
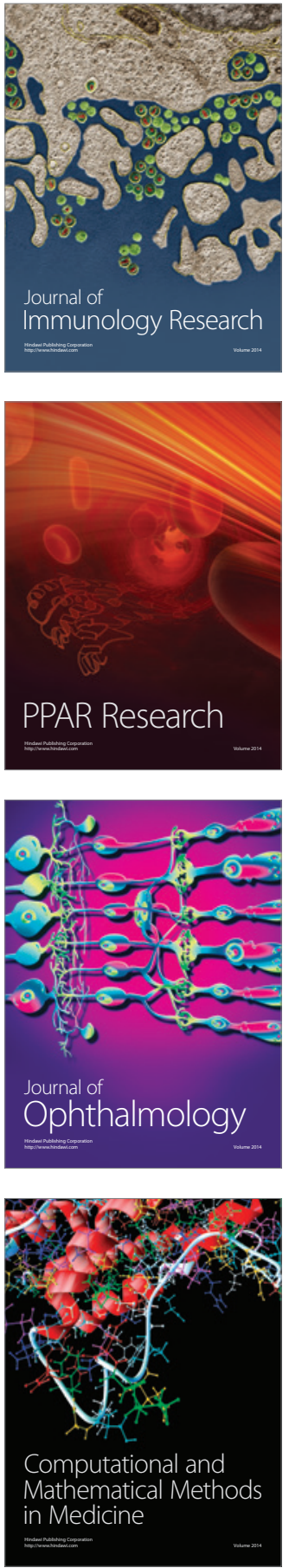

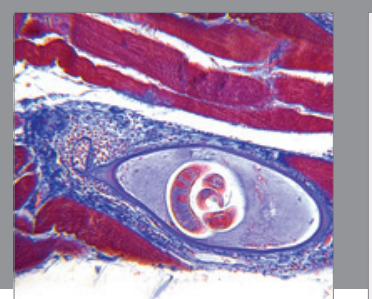

Gastroenterology Research and Practice

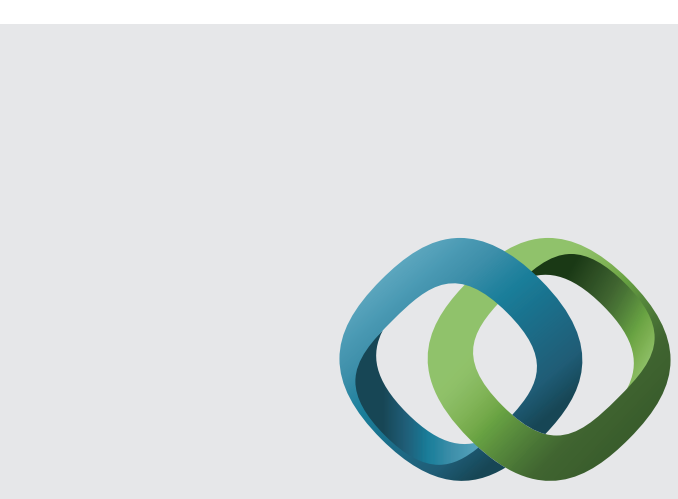

\section{Hindawi}

Submit your manuscripts at

http://www.hindawi.com
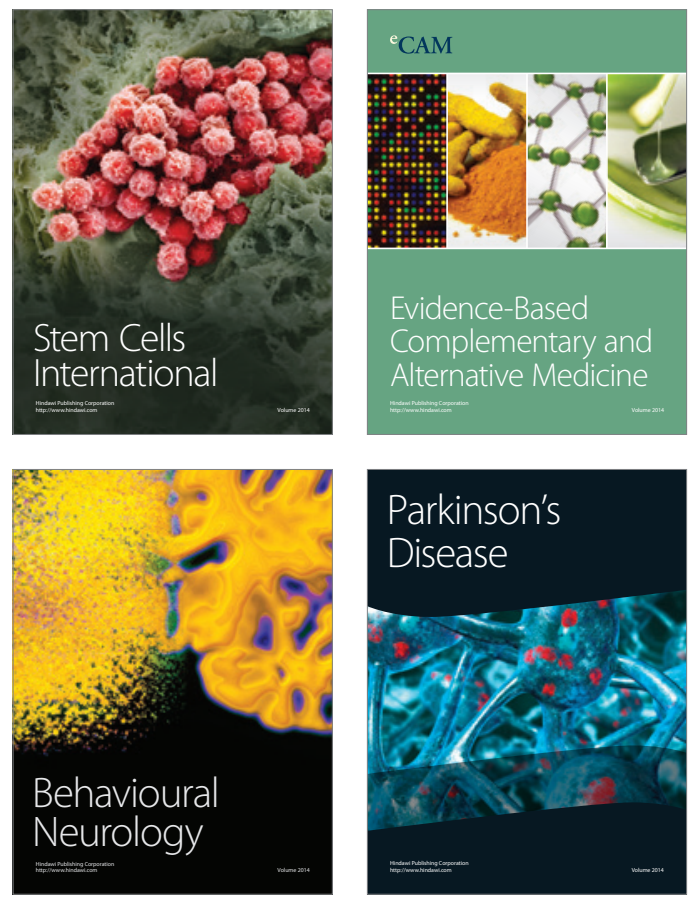
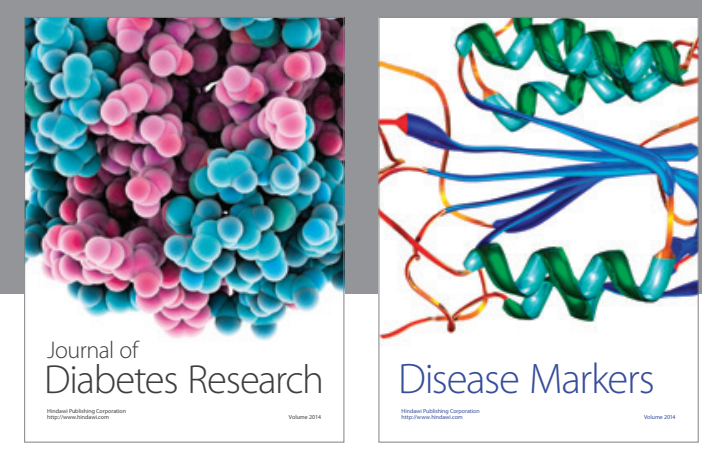

Disease Markers
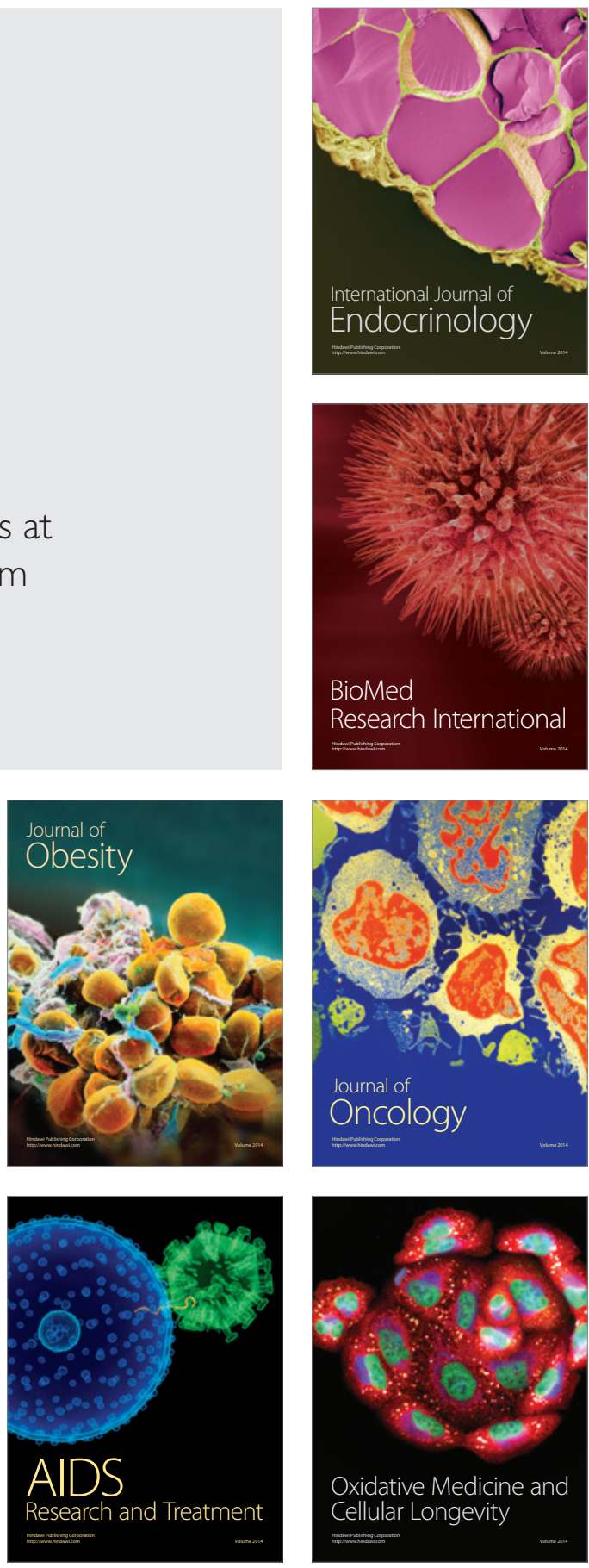